\title{
Evaluation of an Antimicrobial Potentials of Indigenous Plant Extracts Against Pathogenic Organisms
}

\author{
Bhusare D. U. \\ Digambarrao Bindu College, Bhokar, Dist, Nanded, (MS), India
}

\begin{abstract}
The present investigation aimed to evaluate in vitro antimicrobial activity of water, ethanol and acetone extract of three well known medicinal plants against five pathogenic microorganisms such as $E$. coli, P. aeruginosa, B. subtilis, S. typhi and S.aureus. These three medicinal plants were combined and showed a highly significant degree of activity against all the test organisms. The integrated plant extract in water solvent revealed highest $18 \mathrm{~mm}$ zone against $E$. coli.
\end{abstract}

Keywords: Plant extract, pathogenic organism, standard antibiotics

\section{Introduction}

Ayurveda, the Indian indigenous system of medicine, dating back to the Vedic ages, has been an integral part of Indian cultures. The term comes from Sanskrit root, Ayu (=life) and Veda (= knowledge). As the name implies, it is not only a science of treatment of the ill but covers the whole gamut of happy life, involving the physical, metaphysical and the spiritual aspects (Shivarajan \& Balchandran, 1994). According to the World Health Organization $80 \%$ of people worldwide rely chiefly on traditional, largely herbal, medicine to meet their primary healthcare needs. This is because of ease in availability and low price in contrast to the costly inputs of allopathic medicines and technology. (Jager, 2003 and Renzo et al., 2007). Plants have been an essential part of human society since the civilization started. Medicinal plants are boon of nature to cure a number of ailments of human beings (Indrayan et al., 2004 and Edwin et al., 2006). Practitioners of ayurveda and Unani system of Medicine regularly employ a large number of Indian medicinal plants as antibiotic agents. In many parts of the world medicinal plants were used against bacterial, virus and fungal infections. Our country represents a storehouse of genetic diversity of plants. Over the last 40 years, intensive efforts have been made to discover clinically used antibacterial and antifungal drugs. (Shankar et al., 2005 and Fazly et al., 2007).

\section{Materials and Methods}

\section{Collection of Indigenous Plant Samples}

The fresh plant materials were used for the present investigation such as Ginger (Zingiber officinale), Garlic (Allium sativam) and Turmeric (Curcuma longa) collected from Agricultural University, Parbhani.

\section{Preparation of Plant Extracts}

Collect plant material such as fruit and leaves of ginger, garlic and turmeric. The plant material were chopped in to small pieces and washed thoroughly 2-3 times with running water and once with sterile distilled water. Stem bark, leaves and fruit (10 g) material was then air dried and makes a crystalline (powdered) form of each material. The powder was then soaked in different solvents such water (W), ethanol (E) and acetone (A) for 1 hrs. Take a clean and dry separating funnel, mixed well and filter by using whatman filter paper no 1. After filtration collect filtrate and suspended plant residue were removed by centrifugation $\left(10000 \mathrm{rpm}, 30 \mathrm{~min}, 4^{\circ} \mathrm{C}\right)$. The supernatant was evaporated to dryness under reduced pressure. The same procedure applies for remaining plant extracts. The obtained extracts were used against pathogenic organisms (Mahesh and Satish, 2008).

Growth and maintenance of test organism

The cultures of E. coli, P. aeruginosa, B. subtilis, S. typhi and S.aureus were used as a test organism. The purified pathogenic microorganisms were grown on nutrient agar medium and preserved at $2-8^{\circ} \mathrm{C}$.

\section{Preparation of Inoculum}

The bacterial cultures were inoculated in nutrient broth and kept it on rotary shaker incubator at $37^{\circ} \mathrm{C}$ having $120 \mathrm{rpm}$. After incubation it was used as a test culture as an inoculum for to test the antimicrobial activity of plant extracts.

\section{Antimicrobial Activity Assay}

Antimicrobial activity of the aqueous extracts was determined by agar well diffusion method on nutrient agar medium. Well are made on nutrient agar plate using cork borer $(6 \mathrm{~mm})$ and inoculum containing $10^{6} \mathrm{CFU} / \mathrm{ml}$ of bacteria were spread on the medium containing plates. Add $25 \mu \mathrm{l}$ of the plant extract in prepared well. The same process is applied by using $25 \mu \mathrm{l}$ of sterile distilled water on nutrient agar medium as a control. All the plates were incubated for $24 \mathrm{hrs}$ at $37^{\circ} \mathrm{C}$ and measure the zone of inhibition around the well. Kept separate control of ethanol, water and acetone. The streptomycin and kanamycin were used at $20 \mu \mathrm{g} / \mathrm{ml}$ concentration as a reference to determine the sensitivity of tested pathogenic organism (Nihal et al., 2008 and Mahesh and Satish, 2008).

\section{Results and Discussion}

The present investigations ten medicinal plants were taken and used its parts extracts such as leaves, stem bark and 


\section{International Journal of Science and Research (IJSR) \\ ISSN (Online): 2319-7064 \\ Index Copernicus Value (2013): 6.14 | Impact Factor (2015): 6.391}

fruits. All these plant parts are prepared in water, ethanol and acetone as a solvent and tested for antimicrobial activity against test organisms. All these results are compared to standard antibiotics such as streptomycin and kanamycin.

The standard antibiotics are used against all the collected organisms for check its efficiency against the E. coli, $P$. aeruginosa, $B$. subtilis, $S$. typhi and S.aureus. The streptomycin and kanamycin were used at $20 \mu \mathrm{g} / \mathrm{ml}$ concentration. Both the antibiotics are showed the maximum antimicrobial activity against $S$. aureus as compare to other organisms and the zone of inhibition measured 11 and 10 $\mathrm{mm}$ of streptomycin and kanamycin respectively. According to obtained result the $S$. aureus was more sensitive as compare to remaining pathogens.

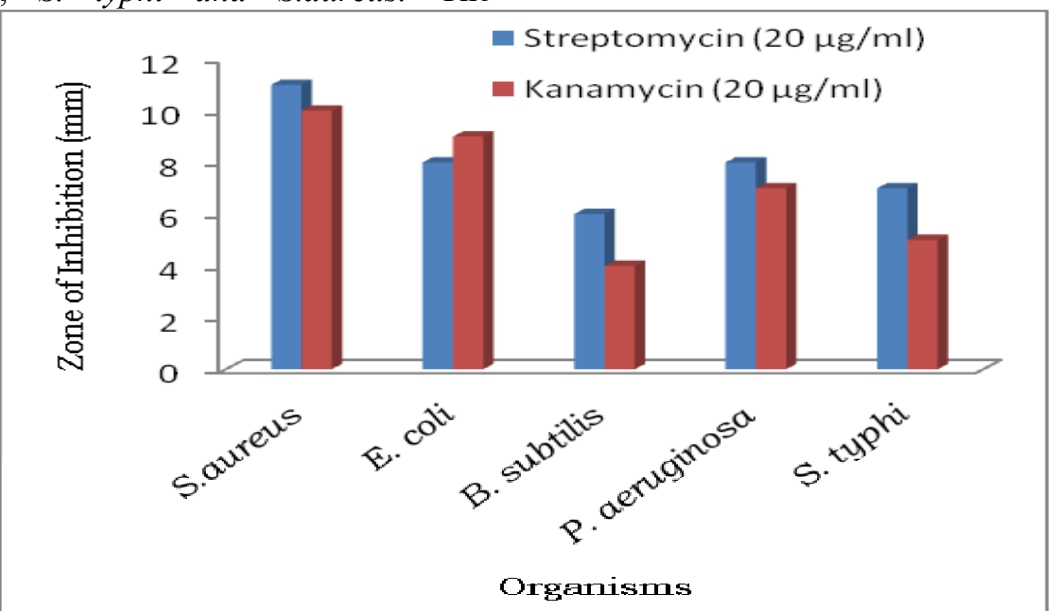

Figure 1: Effect of streptomycin and kanamycin against the pathogenic organisms indicated by zone of inhibition (mm).

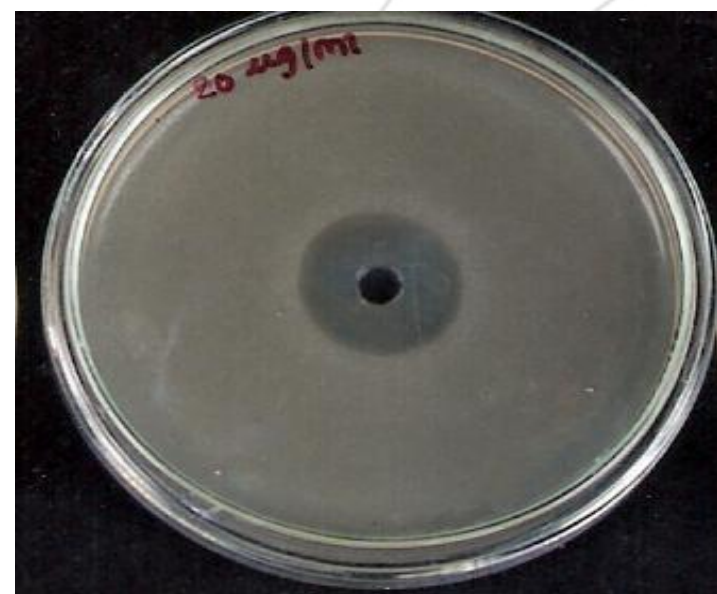

Figure 2: Activity of streptomycin on $S$. aureus showed zone of inhibition
Antimicrobial activity of three individual plant extracts According to obtained results the antimicrobial property of fruit extracts was more than leaves extract of all the medicinal plants. The fruit extracts of turmeric (Curcuma longa) manifested the highest antimicrobial activity against the test organisms showed in table 1 and 2 and it was measured the mean diameter of inhibition zone $(\mathrm{mm})$. The turmeric extracts was effective against E. aerogenes, E.coli, $K$. pneumoniae, $P$. aeruginosa and streptococcus spp. It was most effective on $S$. aureus and had very little effect on $P$. vulgaris, B. subtilis and L. monocytogenes. Ginger and Garlic extract was exhibited not more than turmeric extract except water and ethanolic extract of garlic exhibited a good antimicrobial property against the B. subtilis. (Seher et al. 2006 and Rao et al., 2006).

Table 1: Antimicrobial activity of leaves extracts against organisms indicated by zone of inhibition (mm).

\begin{tabular}{|c|c|c|c|c|}
\hline $\begin{array}{c}\text { Organism/herbal } \\
\text { extract }\end{array}$ & Solvent & $\begin{array}{c}\text { Zone of Inhibition }(\mathrm{mm}) \\
\text { Ginger }\end{array}$ & $\begin{array}{c}\text { Zone of Inhibition }(\mathrm{mm}) \\
\text { Garlic }\end{array}$ & $\begin{array}{c}\text { Zone of Inhibition }(\mathrm{mm}) \\
\text { Turmeric }\end{array}$ \\
\hline \multirow{3}{*}{ S.aureus } & $W$ & 05 & 04 & 12 \\
& $E$ & 03 & 00 & 13 \\
\hline \multirow{3}{*}{ E.coli } & $W$ & 04 & 03 & 07 \\
& $E$ & 00 & 09 & 09 \\
\hline \multirow{3}{*}{ B. subtilis } & $W$ & 04 & 04 & 06 \\
\hline \multirow{3}{*}{ P. aeruginosa } & $E$ & 07 & 00 & 06 \\
& A & 06 & 10 & 05 \\
\hline \multirow{3}{*}{ S. typhi } & A & 07 & 11 & 02 \\
& $E$ & 03 & 03 & 04 \\
\hline
\end{tabular}

(W - Water Extract, E- Ethanol Extract \& $\mathbf{A}$ - Acetone Extract) 


\section{International Journal of Science and Research (IJSR) \\ ISSN (Online): 2319-7064 \\ Index Copernicus Value (2013): 6.14 | Impact Factor (2015): 6.391}

The zone of inhibition against the S. aureus was 12, 13 and $10 \mathrm{~mm}$ on water, ethanol and acetone extracts respectively. The antimicrobial activity against the $B$. subtilis was 10 and $11 \mathrm{~mm}$ on water and ethanol extracts but the same extract was not more active in an acetone extract and the zone of inhibition was $03 \mathrm{~mm}$. all the results presented in table 1 . In the same way the plant fruits were taken for the antimicrobial activity against the same organisms. During this investigation the solvent systems was responsible to increase the antimicrobial property of the plant extract. The obtained results were presented in table 1 .

The antimicrobial activity of fruit extract on organisms showed the extract of turmeric was more effective against the $S$. aureus. In which the ethanol solvent showed the maximum antimicrobial activity against the same. The zone of inhibition was $13 \mathrm{~mm}$. while 10 and $12 \mathrm{~mm}$ zone of inhibition was showed in water as well as acetone extracts. The obtained results tabulated in table 2 .

Table 2: Antimicrobial activity of Fruit extracts against organisms indicated by zone of inhibition $(\mathrm{mm})$.

\begin{tabular}{|c|c|c|c|c|}
\hline $\begin{array}{l}\text { Organism/ } \\
\text { herbal } \\
\text { extract }\end{array}$ & Solvent & $\begin{array}{c}\text { Zone of } \\
\text { Inhibition } \\
(\mathrm{mm}) \\
\text { Ginger }\end{array}$ & $\begin{array}{c}\text { Zone of } \\
\text { Inhibition } \\
(\mathrm{mm}) \\
\text { Garlic }\end{array}$ & $\begin{array}{c}\text { Zone of } \\
\text { Inhibition } \\
(\mathrm{mm}) \\
\text { Turmeric }\end{array}$ \\
\hline \multirow{3}{*}{ S.aureus } & $W$ & 07 & 05 & 10 \\
\hline & $E$ & 08 & 04 & 13 \\
\hline & $A$ & 10 & 08 & 12 \\
\hline \multirow{3}{*}{ E.coli } & $W$ & 04 & 00 & 08 \\
\hline & E & 05 & 07 & 09 \\
\hline & $A$ & 04 & 05 & 06 \\
\hline \multirow{3}{*}{ B. subtilis } & $W$ & 04 & 00 & 10 \\
\hline & $E$ & 07 & 05 & 08 \\
\hline & $A$ & 00 & 07 & 06 \\
\hline \multirow{3}{*}{$\begin{array}{c}P . \\
\text { aeruginosa }\end{array}$} & $W$ & 04 & 00 & 04 \\
\hline & $E$ & 05 & 07 & 06 \\
\hline & $A$ & 08 & 00 & 09 \\
\hline \multirow{3}{*}{ S. typhi } & $W$ & 00 & 06 & 08 \\
\hline & $E$ & 04 & 00 & 10 \\
\hline & $A$ & 06 & 04 & 05 \\
\hline
\end{tabular}

(W - Water Extract, E- Ethanol Extract \& $\mathbf{A}$ - Acetone Extract).

\begin{abstract}
Antimicrobial activity of three combined (synergetic) plant extracts on selected pathogens.

Combination of plant extracts enhances its antimicrobial activity against organisms (Rao et al 2006). According to obtained results when combination of crude extract was used as an antimicrobial agent then it showed the interesting results that the combined all the extracts showed its inhibitory property where as some individual had no antimicrobial activity. The combination of acetone crude extracts of garlic and gingers (A) both leaves and fruit extracts yielded a good result against $S$. aureus it showed a $11 \mathrm{~mm}$ and $13 \mathrm{~mm}$ zone of inhibition respectively.
\end{abstract}

Ginger and turmeric (B) mixture showed maximum activity on S.aureus, E.coli, B. subtilis and P. aeruginosa in which the ethanol extract gives more significant role to control it. The obtained result presented in table 3 and 4 . Of all the solvent extracts ethanol extract of leaves and fruit of garlic and turmeric mixture had a good antimicrobial activity against S.aureus it was $12 \& 15 \mathrm{~mm}$ zone of inhibition. While the water extract of fruit had a better activity on, $B$. subtilis as compare to other and it was $17 \mathrm{~mm}$ inhibition zone.

Table 3: Combined antimicrobial activity of leaves extracts of different plants on selected pathogens indicated by zone of inhibition $(\mathrm{mm})$.

\begin{tabular}{|c|c|c|c|c|c|}
\hline $\begin{array}{c}\text { Organism/ } \\
\text { herbal } \\
\text { extract }\end{array}$ & Solvent & $\begin{array}{c}\text { Zone of } \\
\text { Inhibition } \\
(\mathrm{mm}) \\
\text { A }\end{array}$ & $\begin{array}{c}\text { Zone of } \\
\text { Inhibition } \\
(\mathrm{mm}) \\
\text { B }\end{array}$ & $\begin{array}{c}\text { Zone of } \\
\text { Inhibition } \\
(\mathrm{mm}) \\
\text { C }\end{array}$ & $\begin{array}{c}\text { Zone of } \\
\text { Inhibition } \\
(\mathrm{mm}) \\
\text { D }\end{array}$ \\
\hline \multirow{3}{*}{ S.aureus } & $W$ & 7 & 11 & 09 & 12 \\
\hline & E & 10 & 12 & 06 & 10 \\
\hline & $A$ & 11 & 10 & 07 & 11 \\
\hline \multirow{3}{*}{ E.coli } & $W$ & 06 & 10 & 05 & 14 \\
\hline & $E$ & 07 & 12 & 08 & 12 \\
\hline & $A$ & 06 & 09 & 09 & 10 \\
\hline \multirow{3}{*}{ B. subtilis } & $W$ & 08 & 13 & 11 & 15 \\
\hline & $E$ & 05 & 12 & 09 & 14 \\
\hline & $A$ & 06 & 06 & 10 & 14 \\
\hline & $\bar{W}$ & 04 & 08 & 09 & 12 \\
\hline$P$. & $E$ & 05 & 09 & 08 & 11 \\
\hline aeruginosa & $A$ & 04 & 11 & 05 & 11 \\
\hline \multirow{3}{*}{ S. typhi } & $W$ & 00 & 07 & 07 & 13 \\
\hline & $E$ & 06 & 06 & 09 & 11 \\
\hline & $A$ & 05 & 11 & 10 & 12 \\
\hline
\end{tabular}

(A: Ginger + garlic, B: Ginger + turmeric, C: Garlic + turmeric, \& D: Ginger + garlic + turmeric)

Garlic and turmeric combination also showed an antimicrobial activity against all organisms. The particular combination was more significant against $B$. subtilis at all solvent extract. The water extract showed an 11 and $10 \mathrm{~mm}$ zone of inhibition of leaves and fruit extract respectively. Whereas ethanol extract of leaves and fruit showed 09 and $11 \mathrm{~mm}$ and acetone extract gives 10 and $12 \mathrm{~mm}$ inhibition zone against $B$. subtilis. This mixture was also active against $S$. typhi in which the acetone extracts showed more significant activity as compare to remaining two solvent extracts and it was 10 and $10 \mathrm{~mm}$ inhibition zone of leaves and fruit extract respectively.

The garlic, ginger and turmeric widely applicable for most of the medical as well as therapeutic processes in Ayurvedic treatments (Shivarajan et al. 1994 and Edwin et al. 2006). These three medicinal plants were combined and showed a highly significant degree of activity was observed against all the test organisms. It indicated that all the test organisms are more sensitive to garlic; ginger and turmeric leaves and fruit extract as compare to previously used extracts. The water extract of fruit was more effective against $18 \mathrm{~mm}$ zone of inhibition

Table 4: Combined antimicrobial activity of fruit extracts of different plants on selected pathogens indicated by zone of inhibition ( $\mathrm{mm})$. 


\section{International Journal of Science and Research (IJSR) \\ ISSN (Online): 2319-7064}

Index Copernicus Value (2013): 6.14 | Impact Factor (2015): 6.391

\begin{tabular}{|c|c|c|c|c|c|}
\hline $\begin{array}{c}\text { Organism/ } \\
\text { herbal } \\
\text { extract }\end{array}$ & Solvent & $\begin{array}{c}\text { Zone of } \\
\text { Inhibition } \\
(\mathrm{mm}) \\
\mathbf{A}\end{array}$ & $\begin{array}{c}\text { Zone of } \\
\text { Inhibition } \\
(\mathrm{mm}) \\
\text { B }\end{array}$ & $\begin{array}{c}\text { Zone of } \\
\text { Inhibition } \\
(\mathrm{mm}) \\
\mathbf{C}\end{array}$ & $\begin{array}{c}\text { Zone of } \\
\text { Inhibition } \\
(\mathrm{mm}) \\
\text { D }\end{array}$ \\
\hline \multirow{3}{*}{ S.aureus } & $W$ & 12 & 13 & 10 & 12 \\
\hline & E & 10 & 15 & 07 & 13 \\
\hline & $A$ & 13 & 11 & 08 & 12 \\
\hline \multirow{3}{*}{ E.coli } & $\bar{W}$ & 09 & 12 & 06 & 18 \\
\hline & $E$ & 10 & 12 & 09 & 15 \\
\hline & $A$ & 08 & 10 & 11 & 12 \\
\hline \multirow{3}{*}{ B. subtilis } & $W$ & 12 & 17 & 10 & 14 \\
\hline & $E$ & 10 & 13 & 11 & 15 \\
\hline & $A$ & 09 & 10 & 12 & 17 \\
\hline \multirow{3}{*}{ P. aeruginosa } & $\bar{W}$ & 08 & 10 & 14 & 14 \\
\hline & E & 09 & 12 & 10 & 12 \\
\hline & $A$ & 06 & 13 & 07 & 11 \\
\hline \multirow{3}{*}{ S. typhi } & $W$ & 07 & 08 & 09 & 16 \\
\hline & E & 09 & 07 & 11 & 10 \\
\hline & 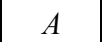 & 08 & 10 & 10 & 13 \\
\hline
\end{tabular}

(A: Ginger + garlic, B: Ginger + turmeric, C: Garlic + turmeric \& D: Ginger + garlic + turmeric)

Garlic and turmeric leaves extracts were found to be more effective than ginger. Garlic leaves extract was active against B. subtilis in water and ethanolic solvent while turmeric leaves extracts active against $S$. aureus in all solvents. The leaves extracts of turmeric was showed antimicrobial potential against $S$. aureus. The fruit extract of turmeric was also active against the $S$. aureus in all solvents. The synergetic action may enhance the antimicrobial activity against the organisms and from result we can concluded that the combined extracts increases its activity. The mixtures of ginger, garlic and turmeric leaves as well as fruit extracts in all solvents were found to be active against the S.aureus, E.coli, B. subtilis, P. aeruginosa and S. typhi.

On the contrary the results of present investigations clearly indicated the antimicrobial activity vary with the plant materials and used solvents. Thus the study ascertains the value of plants used in ayurveda which could be of considerable interest to the development of new drug.
[6] Jager A. K., Evaluation of antibacterial activity of traditionally prepared South African remedies for infection. South African J. of botany vol. 69, 598-600, 2003.

[7] Mahesh.B and Satish.S. Antimicrobial activity of some important medicinal plant against plant and human pathogens. World Journal of Agricultural Sciences 4 (S): 839-843, 2008.

[8] Nihal Dogruoz1, Zuhal Zeybek1*, Ali Karagoz. Antibacterial Activity of Some Plant Extracts. IUFS J Biol, 67(1):17-21, 2008.

[9] Rao M. R. Reddy I. B. and Rammana J. Antimicrobial activity of some Indian medicinal plants Ind. J. of microbio. Vol.46,259-262,2006

[10]Ray p. Rath C.C. Mishra R. K. Antifungal activity of turmeric extract against three dermatophytes. J. of microbiology world 4(2), 123-126, 2002.

[11]Renzo Alberto Ccahuana-Vasquez ,Silvana Soléo Ferreira dos Santos, Cristiane Yumi Koga-Ito, Antonio Olavo Cardoso Jorge. Antimicrobial activity of Uncaria tomentosa against oral human pathogens. Braz Oral Res; 21(1):46-50, 2007.

[12] Shivarajan.V.V and Indira Balchandran. Ayurvedic Drugs and their plant sources. Oxford and IBH publishing Co. PVT.LTD, 1994.

\section{References}

[1] Edwin E, Sheela E, Gupta S. Jain R. Pharmacognostical and preliminary phytochemical studies on leaves of Emblica officinallis International J. of plant sciences. 2006.

[2] Fazly Bazzaz B. S and Maryam Motevaly Haghi. Antibacterial activity of Total Extracts and Essential oil of Nigella Sativa L. Seeds in Mice. Pharmacolgyonline 2: 429-435, 2007.

[3] Gislene G. F. Nascimento, Juliana Locatelli, Paulo C. Freitas, Giuliana L. Silva. Antimicrobial activity of plant extract and phytochemicals on antibiotic resistant bacteria. Brazilian Journal of Microbiology 31:247-256, 2000.

[4] Goswami B. K and Rajesh Kumar Pandey. Sustainable plant protection- a better prospective for the indian farmers. 2009.

[5] Indrayan, A.K.Vimla Yadav, Pradip K. Tyagi and Manoj Kumar. Antibacterial activity of the dye from rhizome of Arnebia nobilis Indian J. of Microbio. 44, 69-71, 2004. 